\title{
Plasma rico em plaquetas para reparação de falhas ósseas em cães
}

\author{
Platelet-rich plasma for canine bone restoration
}

\begin{abstract}
Anna Laeticia Trindade Barbosa ${ }^{*}$ Ricardo Junqueira Del Carlo $^{\text {II }}$ Hayala Castro Gomes ${ }^{\text {III }}$ Aécio Carlos de Oliveira ${ }^{\mathrm{IV}}$ Betania Souza Monteirov ${ }^{\mathrm{V}}$ Brunna Nadur Del Carlo $^{\mathrm{IV}}$
\end{abstract}

RESUMO

As plaquetas chegam rapidamente ao local da ferida e liberam múltiplos fatores de crescimento (FC) $e$ citocinas que contribuem para a reparação óssea e aumentam a vascularização local. O Plasma Rico em Plaquetas (PRP) concentra as plaquetas e os FC liberados por elas, aceleram a formação óssea e melhora a qualidade do trabeculado. Este trabalho apresenta um protocolo para confecção de PRP e demonstra alguns aspectos da sua utilização na reparação óssea de cães. O protocolo foi desenvolvido a partir de sangue coletado por punção jugular em três cães adultos, pesando em média $20 \mathrm{~kg}$. Para avaliação da aplicação clínica e dos aspectos da reparação óssea, foram criadas duas falhas mediais no terço proximal de cada tíbia. Assim, a falha 1 não foi preenchida, constituindo o controle, a falha 2 foi preenchida com 3mg de enxerto ósseo autógeno da crista da tíbia, a falha $3 \mathrm{com}$ gel de plaquetas (PRP) e falha a número $4 \mathrm{com}$ a associação PRP e $3 \mathrm{mg}$ de enxerto ósseo autógeno. O protocolo laboratorial proposto mostrou-se de fácil execução e de baixo custo e possibilitou a concentração adequada de plaquetas no PRP final, cujo número foi dependente da contagem inicial no sangue total de cada animal. A comparação da radiopacidade na região da falha, em todos os tratamentos, e ao longo do tempo demonstrou que o PRP associado ao enxerto determinou maior precocidade e uniformidade de radiopacidade, quando comparado à falha preenchida pelo PRP e ao enxerto usados isoladamente, e sendo que ambos determinam melhores resultados de preenchimento que a falha mantida sem tratamento.

Palavras-chave: gel de plaquetas, enxerto autógeno, fatores de crescimento.

\begin{abstract}
The platelets arrive quickly at the injury site and release several growth factors (GF) and citokines that contribute to bone repair and increasing local vascularization. The Platelet-rich Plasma (PRP) concentrates the platelets and their growth factors, increasing the rate of bone formation and better quality of trabecular bone. This research presents a protocol to PRP formulation and demonstrates some aspects about the use in canine bone repair. In this protocol blood was obtained from the jugular ven of tree adult dogs with medium weight of $20 \mathrm{~kg}$ to produce PRP. Two defects in the medial aspect of proximal third of the tibia were surgically created to evaluate the clinical and radiographic aspect of PRP. The control defect wasn't treated.The defect 2 was filled with $3 \mathrm{mg}$ of autogenous bone graft from the tibia crest. The defect 3 was filled with PRP alone and the number 4 with PRP in the combination with $3 \mathrm{mg}$ autogenous bone graft. The proposed laboratory protocol demonstrated to be easy to execute at low cost. Further, it was adequate to concentrate platelets in final PRP, whose number was dependent on the blood from each dog. Comparing the defect regions, was concluded that the association of PRP and bone graft showed greater precocity and uniform radiopacity than the PRP or bone graft isolated, although both determine better results than the defect without treatment.
\end{abstract}

Key words: platelet gel, autogenous graft, growth factors.

\section{INTRODUÇÃO}

Entre os tecidos altamente organizados, o osso destaca-se por exibir grande potencial regenerativo, sendo capaz de reparar fraturas e defeitos

\footnotetext{
IPrograma de Pós-graduação em Medicina Veterinária, Universidade Federal de Santa Maria (UFSM). Endereço para correspondência: R. Dr. Bozano 646, apt 01, Centro, 97015-000, Santa Maria, RS, Brasil. E.mail: laeticiatrindade@yahoo.com.br*Autor para correspondência.

IIDepartamento de Veterinária (DVT), Universidade Federal de Viçosa (UFV),Viçosa, MG, Brasil.

IIICurso de Medicina Veterinária, Centro de Ciências Biológicas e da Saúde (CCB), UFV, Viçosa, MG, Brasil.

IVDVT, UFV, Viçosa, MG, Brasil.

${ }^{\text {IV} P r o g r a m a ~ d e ~ P o ́ s-g r a d u a c ̧ a ̃ o ~ e m ~ M e d i c i n a ~ V e t e r i n a ́ r i a, ~ D V T, ~ U F V, ~ V i c ̧ o s a, ~ M G, ~ B r a s i l . ~}$
} 
locais com semelhança estrutural, desde que estejam presentes elementos fundamentais como células osteocompetentes, mediadores biológicos (entre eles os fatores de crescimento), matriz associada a condições locais de vascularização e suporte estrutural (CANDINI, 2001).

O plasma rico em plaquetas (PRP) é uma fonte autógena e barata de fatores de crescimento (FC), preparado a partir de pequena quantidade de sangue total retirado do próprio paciente, no período préoperatório (LIEBERMAN et al., 2002). O PRP apresenta em sua constituição o plasma, os leucócitos e as plaquetas. No plasma estão contidos diversos fatores de coagulação (GOLDBERG, 1997), os leucócitos que conferem resistência natural aos agentes infecciosos e imunológicos, e as plaquetas que sofrem degranulação nos sítios de lesão liberando os FC (MARX \& GARG, 1999).

A sinalização realizada pelos FC é mediada por receptores de membrana localizados na superfície das células em que atuam, determinando especificidade de ação frente a cada situação e promovendo proliferação ou inibição (LENHARO \& COSSO, 2001). Os FC influenciam a divisão celular, a síntese de matriz e a diferenciação tecidual. Estudos têm apontado-os como importantes na reparação óssea, na formação de cartilagem e na reparação de tecidos musculares e esqueléticos (LIEBERMAN et al., 2002). Eles são osteoindutores, agindo nas células osteoprogenitoras diferenciando-as e auxiliando na osteogênese (LEMOS et al., 2002).

Pelo menos três fatores são derivados dos grânulos plaquetários: fator de crescimento derivado de plaquetas (PDGF), fator de crescimento e transformação beta (TGF- $\beta$ ) e fator de crescimento semelhante à insulina [IGF] (GIANNOBILE, 1996).

PDGF é uma glicoproteína cujas atividades são mitogênese, angiogênese, ativação de macrófagos e promoção de quimiotaxia (MARX \& CARLSON, 1996). $\mathrm{O}$ aumento de sua quantidade inicial propicia maior atividade das células osteocompetentes do que ocorreria no enxerto ou coágulo apenas, determinando rapidez na formação óssea e melhor qualidade do trabeculado (BRANDÃO, 2005).

TGF-ß é uma superfamília que inclue TGF$ß 1$, TGF- $\beta 2$ e proteínas morfogenéticas ósseas (BMP). Presume-se que TGF- $\beta 1$ e $\beta 2$ sejam lançados pelas plaquetas após a formação do coágulo na fratura, estando associados à proliferação de tecido periosteal no período inicial da consolidação. No entanto, sua ação mais intensa ocorre durante a proliferação celular cartilaginosa e a ossificação endocondral (MARX \& GARG, 1999; LIEBERMAN et al., 2002).
O IGF é mitogênico para as células da linhagem osteoblástica e estimulador da osteogênese a partir dos osteoblastos diferenciados. Quando combinado com outros FG, como PDGF ou TGF- $\beta$, pode acelerar a osteogênese (GIANNOBILE, 1999).

Este trabalho apresenta um protocolo para confecção de plasma rico em plaquetas (PRP) e alguns aspectos da sua utilização na reparação de falhas ósseas experimentais na tíbia de cães.

\section{MATERIAL E MÉTODOS}

Foram utilizados três cães adultos, clinicamente saudáveis, sem raça definida, sendo duas fêmeas e um macho, pesando $20 \mathrm{~kg}$ em média. Inicialmente foram realizados hemograma, leucograma e contagem plaquetária, determinando o padrão do sangue total para cada cão. O protocolo laboratorial foi elaborado a partir dos protocolos apresentados por CANDINI (2001), ROSSI (2001) e LEMOS et al. (2002), Todas as etapas foram desenvolvidas em capela de fluxo laminar, sob luz ultravioleta e com utilização de luvas esterilizadas.

As diferentes etapas para preparo do PRP foram, pela ordem, as seguintes: por meio de punção jugular obteve-se $18 \mathrm{~mL}$ de sangue venoso colhidos em 4 tubos de vacutainer de 4,5mL, contendo citrato de sódio. O conteúdo dos tubos foi homogeneizado e centrifugado a $1300 \mathrm{rpm}$, por 8 minutos. Após a centrifugação, a porção celular (leucócitos e hemácias) precipitou na porção final do tubo e o plasma sobrenadou, existindo uma pequena camada intermediária, a zona de névoa, constituída de leucócitos, plaquetas maiores e hemácias. O plasma foi pipetado dos tubos e acondicionado em outros dois tubos. Pipetou-se também $200 \mu \mathrm{L}$, por tubo, da zona de névoa, que foram reservados em um terceiro tubo. Posteriormente, esta suspensão será utilizada juntamente com o PRP para a obtenção do coágulo. Realizou-se uma nova centrifugação dos dois tubos contendo o plasma, a 1300rpm, por oito minutos. Ao retirar os tubos da centrífuga, observou-se o botão de plaquetas no fundo de cada tubo e o plasma separado, tomando o restante do tubo. O plasma sobrenadante foi retirado, deixando apenas $450 \mu \mathrm{L}$, formados pelo plasma e o botão plaquetário. Ao agitar o tubo, ocorreu a resuspensão do botão e observou-se o PRP em sua coloração normal. Foram adicionados $50 \mu \mathrm{L}$ da zona de névoa aos $450 \mu \mathrm{L}$ de PRP em cada tubo, obtendo o PRP final. Separou-se, em uma seringa, uma alíquota de $25 \mu \mathrm{L}$ $(0,25 \mathrm{~mL})$ de soluplastinc, para cada tubo de PRP, seguindo a proporção de $1: 2$, ou seja, $0,25 \mathrm{~mL}$ do coagulante para $0,5 \mathrm{ml}$ de PRP. Acondicionaram-se os 
dois tubos de PRP final e as duas seringas contendo soluplastin em uma caixa de isopor identificada com o nome do cão. No momento do uso do PRP, a alíquota contendo soluplastin foi adicionada ao tubo contendo o PRP final para confecção do gel de plaquetas.

A checagem do PRP foi obtida pela contagem do número de plaquetas, em máquina automática, que, segundo LEMOS et al. (2002), deve ser superior a 1.000.000 de plaquetas em $1 \mu \mathrm{L}$ para ser considerado positivo. Imediatamente após a obtenção do PRP final, cada animal foi preparado para os procedimentos cirúrgicos. Foram pré-anestesiados com acepromazina $\left(0,1 \mathrm{mgkg}^{-1}, \mathrm{IV}\right)$, submetidos à indução anestésica com tiopental sódico $\left(12,5 \mathrm{mgkg}^{-1}, \mathrm{IV}\right)$, e anestesiados com halotano vaporizado por oxigênio. No período préoperatório, os animais receberam o antibiótico enrofloxacina $\left(10 \mathrm{mgkg}^{-1}, \mathrm{IM}\right)$ e o analgésico monofenilbutazona $\left(0,15 \mathrm{mLkg}^{-1}, \mathrm{IV}\right)$.

Os animais foram posicionados de forma a permitir a abordagem cirúrgica à porção medial do terço proximal da tíbia. Em cada membro, foram realizadas duas falhas circunferenciais na cortical óssea até a exposição do canal medular, com $0,5 \mathrm{~cm}$ de diâmetro e distancia de $1,0 \mathrm{~cm}$ entre elas, por meio de trefina cirúrgica $^{\mathrm{b}}$.

A falha proximal do membro pélvico esquerdo (falha 1) foi mantida vazia, constituindo o controle. A falha distal (falha 2) foi totalmente preenchida com $3 \mathrm{mg}$ de enxerto ósseo esponjoso coletado na crista da tíbia do mesmo membro e no mesmo tempo cirúrgico.

No membro pélvico direito, após a confecção das falhas proximal e distal, coletou-se $3 \mathrm{mg}$ de enxerto ósseo autógeno da crista da tíbia, que foi colocado dentro de um dos frascos contendo o PRP autógeno previamente preparado. Adicionou-se, então, a alíquota de soluplastin e, após resuspensão, procedeu-se ao aquecimento com o calor de uma das mãos por 20 segundos. Dessa forma, foi confeccionado o gel de plaquetas contendo em seu interior o enxerto ósseo autógeno (Figura 1A), que foi aplicado à falha

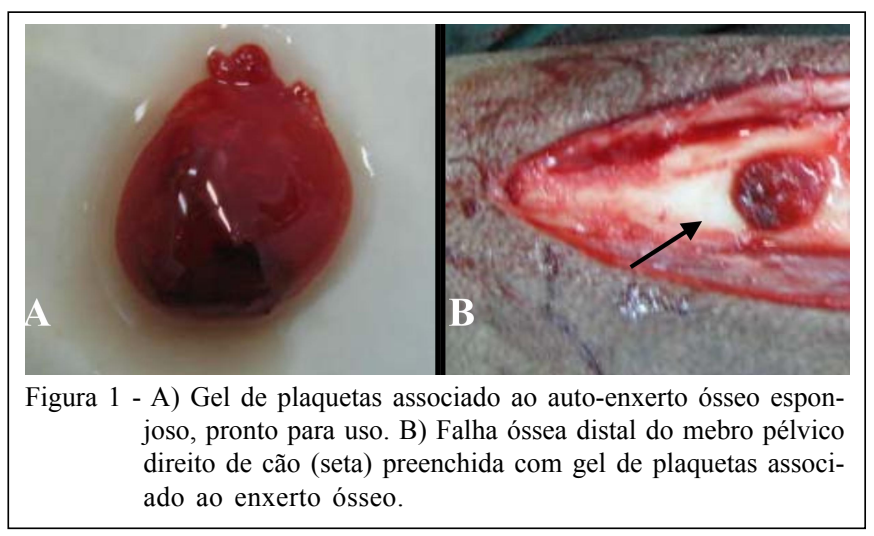

distal ou falha 3 (Figura 1B). A falha proximal (falha 4) foi preenchida apenas com o gel de plaquetas. Em ambos os membros, ao término dos procedimentos, o tecido subcutâneo e a pele foram suturados de forma rotineira.

Os cães permaneceram em baias individuais, e foram avaliados diariamente. Os membros operados foram radiografados logo depois da cirurgia, após 7, 15 e 30 dias, com objetivo de avaliar o grau de preenchimento ósseo das falhas, determinado pela radiopacidade na área da falha.

\section{RESULTADOS E DISCUSSÃO}

O protocolo laboratorial proposto foi de fácil execução e de baixo custo. Ele permitiu a adequada concentração de plaquetas (Tabela 1) em número superior a $1.000 .000 \mu^{-1}$, que foi descrito como adequado por LEMOS et al. (2002). Recomenda-se a manutenção dos procedimentos laboratoriais durante o préoperatório imediato, como apresentado, uma vez que a realização das diversas etapas no período transoperatório acarreta atraso nos tempos cirúrgicos e conseqüentemente maior período anestésico.

Após a primeira centrifugação, foi possível separar o plasma sobrenadante em dois tubos para ser centrifugado novamente e a zona de névoa em um terceiro tubo. A zona de névoa é composta pelas hemácias e plaquetas maiores que dão mais consistência ao gel de plaquetas (ROSSI, 2001), e por leucócitos que, segundo MARX \& GARG (1999), conferem imunidade ao enxerto, conferindo-lhe resistência natural aos processos infecciosos e alérgicos

$\mathrm{Na}$ contagem celular, não foi observada presença de leucócitos e hemácias no PRP inicial, enquanto que na zona de névoa houve quantidade significativa de plaquetas e leucócitos e algumas hemácias. Portanto, foi imprescindível sua adição ao PRP, garantindo, além da resistência ao enxerto, maior consistência ao gel, determinada pelas hemácias e plaquetas maiores.

Observou-se que o resultado final do número de plaquetas no PRP foi dependente da contagem inicial no sangue total do animal. Quanto maior o número inicial, mais rico em plaquetas foi o PRP (Tabela 1). Portanto, a presença de trombocitopenia ou um número menor de plaquetas são fatores limitantes para realização do procedimento.

No presente estudo, quando foram somados $450 \mu \mathrm{L}$ do plasma que envolvia o botão de plaquetas aos $50 \mu \mathrm{L}$ da zona de 
Tabela 1 - Contagem plaquetária e de leucócitos em $1 \mu \mathrm{L}$ nas diversas etapas do protocolo laboratorial, no sangue dos três cães do experimento.

\begin{tabular}{|c|c|c|c|}
\hline & Animais & Plaquetas $\mu \mathrm{L}^{-1}$ & Leucócitos $/ \mu \mathrm{L}$ \\
\hline \multirow{3}{*}{ Sangue Total } & animal 1 & 244.000 & 12.100 \\
\hline & animal 2 & 418.000 & 35.000 \\
\hline & animal 3 & 341.000 & 36.000 \\
\hline \multirow{3}{*}{$\begin{array}{l}\text { Plasma Rico em Plaquetas } \\
\text { (PRP) Inicial }\end{array}$} & animal 1 & 1.640 .036 & - \\
\hline & animal 2 & 2.809 .570 & - \\
\hline & animal 3 & 2.292 .018 & - \\
\hline \multirow{3}{*}{ Zona de Névoa } & animal 1 & 360.000 & 72.300 \\
\hline & animal 2 & 616.721 & 134.750 \\
\hline & animal 3 & 355.000 & 138.600 \\
\hline \multirow{3}{*}{ PRP Final } & animal 1 & 1.512 .032 & 72.300 \\
\hline & animal 2 & 2.590 .285 & 134.750 \\
\hline & animal 3 & 2.098 .316 & 138.600 \\
\hline
\end{tabular}

névoa e aos $250 \mu \mathrm{L}$ de soluplastin, obteve-se o gel de plaquetas de tamanho semelhante ao da falha óssea. Além disso, a confecção do gel no fundo do tubo de ensaio de $5 \mathrm{~mL}$ determinou formato coincidente com o da falha, facilitando sua deposição no período transoperatório. Ou seja, foi possível definir o volume e o formato do gel previamente ao procedimento cirúrgico de forma coincidente ao tamanho da falha, o que é desejável.

A associação do enxerto ósseo ao PRP, antes da adição do soluplastin, permitiu que o enxerto permanecesse misturado ao gel, ficando bem distribuído em toda a falha e evitando perda durante a aplicação. Ao depositar o gel de plaquetas sobre as falhas, observou-se menor quantidade de sangramento local em relação à quantidade evidenciada quando o enxerto foi utilizado de forma isolada. De acordo com LIEBERMAN et al. (2002), este fato pode ser explicado pelo potencial hemostático plaquetário, à semelhança do observado no foco da fratura, quando ocorre a agregação de plaquetas e o início da cascata de coagulação.

A trombina bovina tópica, anteriormente usada na confecção do gel de plaquetas, é difícil de ser encontrada no mercado brasileiro atualmente, e foi substituída com sucesso pelo soluplastin, formando um gel consistente, assim como observado por ROSSI (2001).

Vinte e quatro horas após os procedimentos cirúrgicos os animais apoiaram o membro ao solo sem manifestação de dor. Durante os primeiros quinze dias, observou-se cura mais rápida da ferida de pele e menor formação de edema nos membros direitos dos cães, que são efeitos que podem ser creditados ao potencial de aceleração da cicatrização tecidual inerente ao PRP
(KNIGHTON et al., 1988). Além disso, GREEN et al. (1997) afirmaram que os FC foram capazes de promover diferenciação de células mesenquimais que estimularam eventos regenerativos.

$\mathrm{Na}$ avaliação radiográfica (Figura 2) no momento zero, observou-se a presença de radiopacidade difusa nas falhas que receberam o enxerto ósseo autógeno isoladamente e associado ao PRP e a radioluscência nas falhas 1 e 4 .

No dia 7 , na falha 2 (Figura 2), preenchida com o auto-enxerto isoladamente, a reparação aconteceu a partir das bordas da falha, especificamente na interface enxerto/osso receptor, provavelmente porque o enxerto encontrou suporte estrutural e vascularização necessárias provenientes da borda do defeito. Já na falha 3 (Figura 2), foram observadas áreas de radiopacidade no centro da enxertia, sugerindo a formação de focos de reparação, que podem ser atribuídos à presença do PRP que, segundo KNIGHTON et al. (1988), contém PDGF em altas concentrações, juntamente com TGF- $\beta 1$, TGF- $\beta 2$ e IGF, que aceleram a angiogênese, estabelecendo assim uma rede vascular precoce, e garantindo maior produção de osteóide em menor tempo.

No dia 15 , houve tendência ao aumento da radiodensidade em pontos localizados no interior das falhas 2 e 3 (Figura 2), inclusive com aspecto semelhante ao do osso receptor, refletindo um mecanismo de osteogênese inerente às células da linhagem osteogênica presentes no interior do enxerto. $\mathrm{O}$ autoenxerto associado ao PRP (falha 3 ) determinou maior preenchimento da falha em razão da ação dos FC osteoindutores nas células osteoprogenitoras, diferenciando-as e auxiliando na osteogênese (LEMOS 


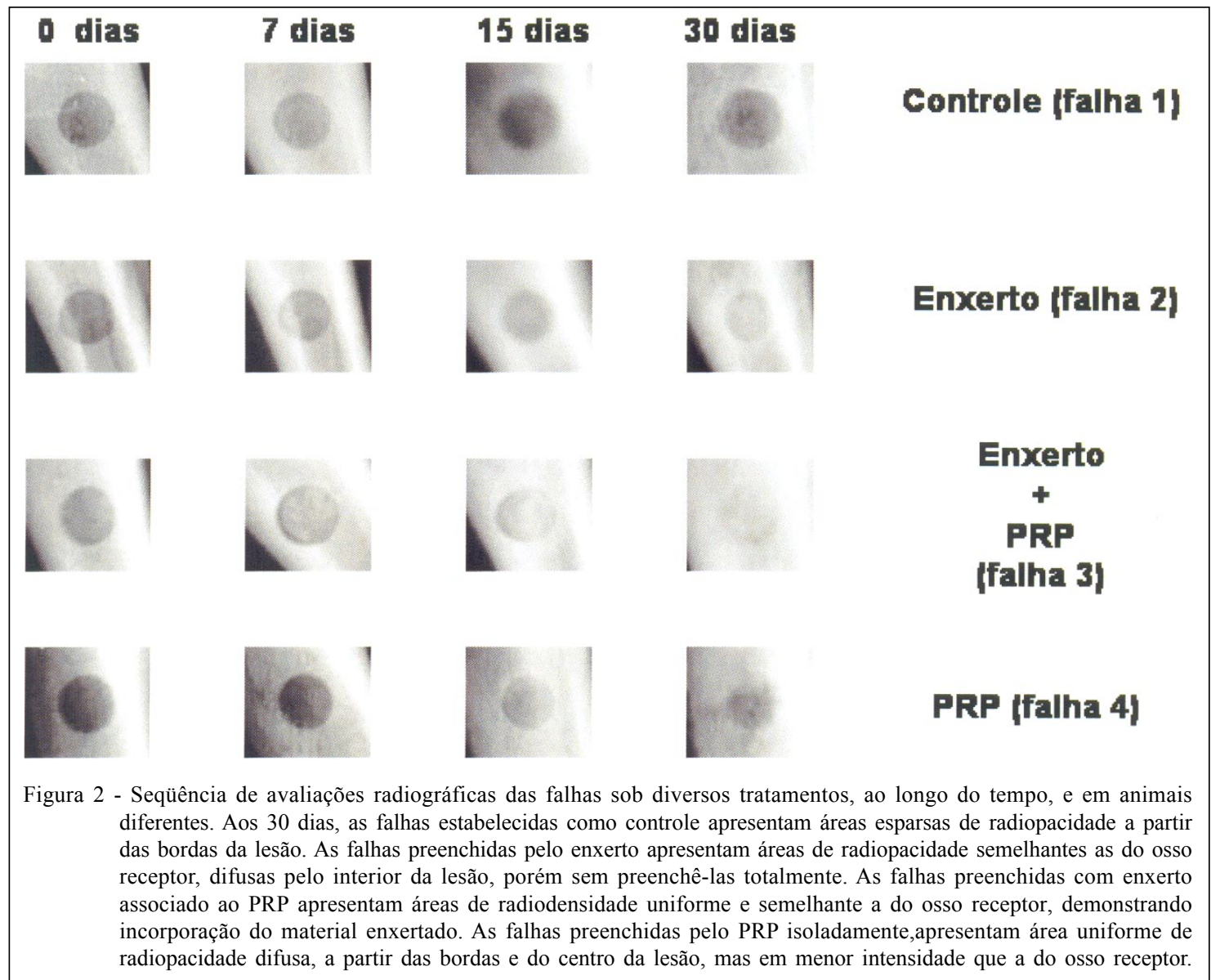

et al., 2002). Além disso, a concentração dos FC no gel de plaquetas é significativamente alta, resultando em 10 a 25 vezes mais PDGF e TGF- $\beta$ do que em um processo osteogênico sem adição de PRP (FLORYAN \& BERGHOFF, 2004).

No dia 30, as falhas estabelecidas como controle apresentavam áreas esparsas de radiopacidade a partir das bordas da lesão. As falhas preenchidas pelo enxerto apresentavam áreas de radiopacidade semelhantes as do osso receptor, difusas pelo interior da lesão, porém sem preenchê-las totalmente. As falhas preenchidas com enxerto associado ao PRP apresentaram áreas de radiodensidade uniforme e semelhante a do osso receptor, demonstrando incorporação do material enxertado. As falhas preenchidas pelo PRP isoladamente apresentavam área uniforme de radiopacidade, difusa, a partir das bordas e do centro da lesão, mas em menor intensidade que a do osso receptor. Para DINATO et al. (2001), o melhor aspecto de preenchimento observado nas falhas preenchidas pela associação deve-se aos FC presentes no PRP, que foram capazes de modular e acelerar os processos ósseos de reparação, por meio dos fatores de crescimento presentes.

Em todas as falhas e ao longo do tempo houve tendência à reparação. Quando comparados os resultados do PRP associado ao enxerto e os do PRP isolado, percebe-se precocidade e uniformidade de radiopacidade. Estes resultados podem ser explicados por MARX (1994), que informou que o período de vida das plaquetas no gel é de 3 a 5 dias e a atividade dos seus fatores se extingue em sete a 10 dias, porém o reforço inicial oferecido é benéfico, pois acelera a cascata de eventos da regeneração óssea. $\mathrm{O}$ enxerto ósseo usado isoladamente determina preenchimento da falha, mas sem a uniformidade de radiopacidade observada a partir dos 15 dias no interior da falha 3 .

\section{CONCLUSÕES}

Nas condições deste experimento, o protocolo laboratorial proposto para confecção de um gel de plaquetas a partir do sangue de cães é exeqüível e de fácil execução e concentra as plaquetas de forma adequada. O gel formado apresenta consistência 
adequada para utilização clínica e, a avaliação preliminar de uso demonstra resultados promissores.

\section{FONTES DE AQUISIÇÃO}

${ }^{\text {a}}$ Soluplastin. Wiener laboratories;

${ }^{b}$ Broca trefina circunscrita. 3i Implantes

\section{COMISSÃO DE ÉTICA E BIOSSEGURANÇA}

O projeto foi aprovado pelo comitê de ética na pesquisa com animais do Departamento de Veterinária da Universidade Federal de Viçosa. Protocolo: 02/2006.

\section{REFERÊNCIAS}

BRANDÃO, G.H.F. Estudo comparativo entre a eficácia clínica de enxertos ósseos (autógenos, alógenos, aloplásticos) com ou sem utilização de plasma rico em plaquetas. 2005. Capturado em 12 de jun. 2005. Online. Disponível na Internet: http://www.medcenter.com.

CANDINI, A.L. Avaliação do efeito do Plasma Rico em Plaquetas fotoestimulado pelo laser de baixa potência no processo de regeneração óssea. 2001. 108f. Dissertação (Mestrado em Engenharia Biomédica) - Programa de Pósgraduação em Bioengenharia, Universidade do Vale do Paraíba.

DINATO, C.J. et al. Plasma rico em plaquetas. In: DINATO, C.J.; POLIDO, D.W. Implantes osseointegrados: cirurgia e prótese. São Paulo: Artes Médicas, 2001. p.315-342.

FLORYAN, K.M.; BERGHOFF, W.J. Intraoperative use of autologous PRP and PRP for orthopedic surgery patients. AORN Journal, v.80, n.4, p.668-674, 2004.

GIANNOBILE, W.V. Periodontal regeneration: potencial role of bone morphogenic proteins. J Period Res, v.29, p.225$235,1996$.

GIANNOBILE, W.V. Periodontal tissue regeneration by polypeptide growth factors and gene transfer. In.: Tissue engennering: applications in maxillofacial surgery and periodontics. Illinois: Quintessense, 1999. p. $231-243$.

GOLDBERG, S. Descomplicando a fisiologia. In: Tratado de fisiologia médica. 8.ed. Porto Alegre: Artes Médicas, 1997. p.61-65.

GREEN, R.J. et al. Immuno localization of platelet-derived growth factor A e B chains and PDGF- alpha e beta receptors in human gingival nounds. J Period Res, v.32, 209-214, 1997.

KNIGHTON, D.R. et al. Oxygen tension regulates the expression of angiogenesis factor by macrophages. Science, v.221, p.379-384, 1988 .

LEMOS, J.J. et al. Utilização de plasma rico em plaquetas em enxertos ósseos - Proposta de um protocolo de obtenção simplificado. 2002. Capturado em 12 jun. 2005. Online. Disponível na Internet: http://www.odontologia.com.br/ artigos.asp? $\mathrm{id}=225 \& \mathrm{idesp}=6 \&$ ler $=\mathrm{s}$

LENHARO, A.; COSSO, F. Fatores de crescimento quando usar? Inovations J, v.5, n.1, p.21-25, 2001.

LIEBERMAN, J.R. et al. The hole of growth factors in the repair bone. J Bone Joint Surg, v.84, n.6, p.1032-1042, 2002 .

MARX, R.E. Clinical application of bone biology to mandibular and maxillary reconstruction. Clin Plast Surg, v.21, p.377$392,1994$.

MARX, R.E.; CARLSON, E.R. The potential role of growth and differentiation factors in periodontal regeneration. Position paper. J Periodontol, v.67, p.545-553, 1996.

MARX, R.E.; GARG, A.K. Bone graft physiology with use of platelet-rich plasma and hiperbaric oxygen. In.:__. The sinus bone graft. Colorado: Quintessense, 1999. p.183-189.

ROSSI, R. Modificação do protocolo simplificado para obtenção do PRP. 2001. Capturado em 12 jun. 2005. Online. Disponível na Internet: http://www.dentalnet.com.br/ bibliotecageral.htm 